DAVID ROBIE is associate

professor and director of AUT

University's Pacific Media Centre.

\section{Spectacular transition \\ in the Pacific}

Asia in the Pacific Islands: Replacing the West, by Ron Crocombe. Suva, Fiji: Institute of Pacific Studies Publications, University of the South Pacific, 2007,622 pp. ISBN 9789820203884

WHILE New Zealand's 2008 $\checkmark$ free trade agreement with China may have ushered in a new era of regional diplomacy, the influence of New Zealand,Australia and European countries in the Pacific is gradually declining. The Cold War rivalry between the US and Soviet camps that impacted heavily on the Pacific in the post-World War period has given way to an intense sovereignty struggle between China and Taiwan. ${ }^{1}$

A growing focus on the Pacific enhances the leverage micro Island states get from raw materials - fisheries, minerals and timber (particularly in Melanesia), providing they don't dissipate too rapidly.

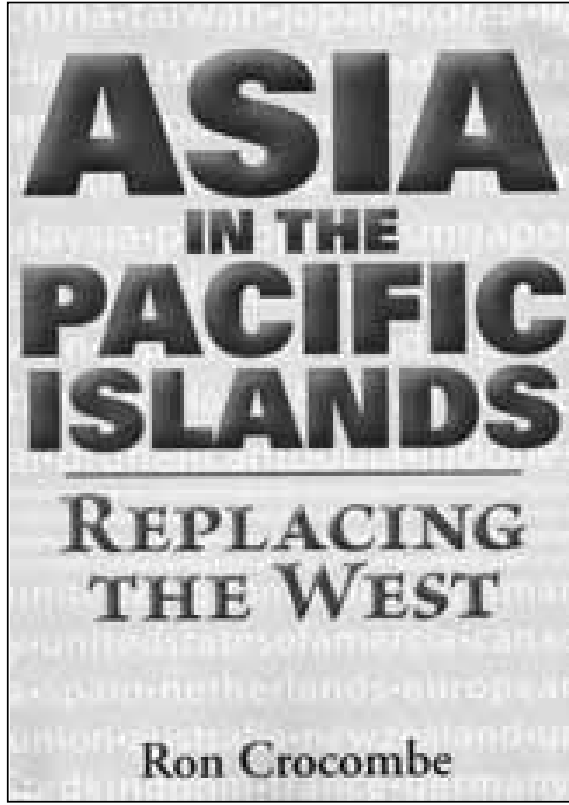

As University of the South Pacific professor emeritus Ron Crocombe argues in this timely book, Asia in the Pacific Islands, the region's 'most valuable non-material "resource" is their ability to take sides on issues that are irrelevant to them, but important to those who want their votes in international forums' (p. 442).

New Zealander Crocombe believes a 'spectacular transition' is under way in the Pacific (p. viii). For the past two centuries, culture, economic, political and other external influences have been 'overwhelmingly Western'. However, this paradigm is now shifting to predominantly Asian influences. 
Asia has already become more important than Western sources in areas such as exports and investments. The overriding concern, Crocombe believes, is the hegemonic ambition of the government of China. He points to looming energy and water crises on the mainlandChina has 21 percent of the world's people, but only seven percent of its fresh water and farmland, three percent of forests and two percent of oil. China has the world's greatest environmental problems, including 16 of the world's most polluted cities and the abandonment of 24,000 villages because of desertification.

Crocombe predicts a rapid acceleration of the movement of Asians into the Pacific Islands-a region of some eight million people (three quarters of them in Papua New Guinea). Already, more than a million Northeast Asians visit Micronesia annually and tourism is likely to grow along with increasing numbers of contract workers, traders and residents.

Some Pacific countries are offering incentives such as the Northern Mariana Islands, whose government offers permanent residence to those who invest more than $\$ 200,000$ - a plan to attract more Japanese and Chinese.

In this 'look North' Pacific context, it is vital, argues Crocombe, that Asian nations are far better informed about and understood. Changes in emphasis for the Pacific education and media sectors are vital. While Pacific media is becoming more powerful and concentrated, Crocombe warns that the region is "entering a "disinformation" era, in which news is distorted by governments, advertisers and other interest groups' - mostly Western at present:

The proportion of information by those aiming to be objective and dispassionate seems to get lower the higher the cost of dissemination. Some of the most creative minds are bought into "public relations", creating [an] artificial demand for goods and services, and "laundering" the actions of governments and commerce. (p. 391)

Crocombe complains that the region's media have been too slow to respond to the growing Asian influence. He notes that the two largest English-language dailies, The Fiji Times and PNG PostCourier, are part of the Murdoch media empire. The French-language dailies are owned by the DassaultHersant-Socpresse conglomerate while the Pacific Daily News in Guam, largest newspaper in the North Pacific - where Asians have had a 
higher profile since the $1970 \mathrm{~s}$ - is part of the US Gannett chain.

While Indian language papers and media ownership is declining, such as in Fiji, Chinese language publications and ownership are growing. Rimbunan Hijau, an ethnic Chinese Malaysian timber conglomerate with regional media interests, founded The National daily in PNG in 1993 to improve its rapacious image. Chinese ethnic ownership is also involved in dailies in Fiji and Vanuatu.
Crocombe has provided a wealth of information that is invaluable for the region as a benchmark text but it would have been improved with tighter editing and more attractive and user-friendly design features.

\section{Note}

1. Fourteen Pacific countries, including Australia and New Zealand, are among the 170 that support one China; six of the 23 global nations that back Taiwan are in the Pacific-Kiribati, Marshall Islands, Nauru, Palau, Solomon Islands and Tuvalu.

\section{$\frac{2}{2}$ \\ Mark Deuze speaks on 'Media Work' What's it like to work in the media today? Sydney, Wednesday, 2 July 2008 \\ Author and academic Mark Deuze will be speaking at the University of Technology, Sydney (UTS) on the working lives of media professionals in this era of cultural and technological convergence.}

Venue: UTS, Building 2, 15 Broadway, Ultimo, Level 4 (entrance level), Room $11(2.4 .11)$

Time: $6 \mathrm{pm}$

Date: Wednesday, 2 July 2008

Free and open to the public.

Hosted by the UTS Australian Centre for Independent Journalism.

The Australian Centre for Independent Journalism aims to stimulate the production of high quality journalism through supporting investigative research, offering continuing professional education courses, publications, events and research grants.

For more information see the Australian Centre for Independent Journalism www.acij.uts.edu.au 